\title{
Antioxidative defense and mitochondrial thermogenic response in brown adipose tissue
}

\author{
Vesna Petrović • Biljana Buzadžić · Aleksandra Korać • \\ Bato Korać
}

Received: 26 June 2009/ Accepted: 19 November 2009/Published online: 13 December 2009

(C) Springer-Verlag 2009

\begin{abstract}
Cold-exposure activates interscapular brown adipose tissue (IBAT) non-shivering thermogenesis that relies primarily on intensification of metabolic rate and uncoupling. During cold-acclimation, uncoupling in IBAT decreases superoxide $\left(\mathrm{O}_{2}{ }^{-}\right)$production and as an adaptive response the activities of manganese and copper, zinc superoxide dismutase (Mn- and CuZn-SOD, respectively) are decreased, as well. However, molecular mechanisms governing this SODs adaptive response are still unsolved. Besides, knowing that NO reinforces IBAT uncoupling, we wondered whether nitric oxide (NO) is taking part in SODs regulation? $\mathrm{Mn}-$ and $\mathrm{CuZn}-\mathrm{SOD} \mathrm{mRNA}$ and protein expression, uncoupling protein 1 (UCP1), nitrotyrosine and nuclear factor-kappa B (NF- $\kappa \mathrm{B})$ immunolabeling, as well as total SOD (tSOD) activity in IBAT of rats subjected to cold $\left(4 \pm 1^{\circ} \mathrm{C}\right)$ for $1,3,7,12,21$ and 45 days and treated by L-arginine or $N^{\omega}$-nitro-L-arginine-methyl ester (L-NAME) were examined. Cold increased UCP1 immunopositivity and decreased tSOD activity during entire cold-acclimation and transiently, (day 3), activated NF- $\kappa \mathrm{B}$ and increased $\mathrm{Mn}$ and CuZn-SOD mRNA expression and nitrotyrosine labeling, suggesting NO involvement in this signaling. However, SODs mRNA expression was decreasing from day 12 till the end of cold-acclimation.
\end{abstract}

V. Petrović · B. Buzadžić · B. Korać $(\bowtie)$

Institute for Biological Research "Siniša Stanković",

Department of Physiology, University of Belgrade,

Bulevar Despota Stefana 142, 11060 Belgrade, Serbia

e-mail: koracb@ibiss.bg.ac.rs

A. Korać

Institute of Zoology, University of Belgrade,

Studentski trg 16, 11000 Belgrade, Serbia
L-arginine augmented and prolonged cold-induced UCP1 and nitrotyrosine immunopositivity, NF- $\kappa \mathrm{B}$ activation and SODs mRNA expression increase, while L-NAME expressed an opposite effect. Related to cold, L-arginine decreased, while L-NAME increased Mn-SOD protein expression. In contrast, neither low temperature nor both treatments applied affected CuZn-SOD protein expression. The results showed that adaptive decrease in SODs activity on uncoupling-decreased $\mathrm{O}_{2}{ }^{-}$production was achieved already at the level of gene transcription and that NO takes part in the regulation of IBAT SOD isoforms.

Keywords Brown adipose tissue $\cdot$ Cold $\cdot$ Mn-SOD . $\mathrm{CuZn-SOD} \cdot \mathrm{NO} \cdot \mathrm{NF}-\kappa \mathrm{B}$

\section{Introduction}

Interscapular brown adipose tissue (IBAT) is the main site of non-shivering thermogenesis [1]. The thermogenic capacity of IBAT relies on its high mitochondrial density and unique presence of uncoupling protein 1 (UCP1) that uncouples phosphorylation from respiration and dissipates proton gradient as heat $[2,3]$. Exposure of animals to cold activates IBAT thermogenic program [4], a complex process consisting of a series of molecular, biochemical and structural tissue changes that recruit a large capacity for tissue oxidative metabolism increase and heat production. However, increase in tissue metabolic activity unavoidably leads to generation of reactive oxygen and nitrogen species (ROS and RNS, respectively), well known mediators of several forms of tissue damage. Cellular homeostasis in these conditions is maintained by an almost perfect match in the tissue antioxidative defense (AD) [5-10]. In addition, we have recently shown that the 
changes in $\mathrm{AD}$ occurring during cold-acclimation should be observed as a part of newly established IBAT homeostasis that characterizes intensive oxidative metabolism, uncoupling, lipolysis and decreased rate of apoptosis [9-11]. Therefore, shown decrease in manganese and copper, zinc superoxide dismutase (Mn- and CuZn-SOD, respectively, EC 1.15.1.1) activity in rats kept at cold for 45 days, accompanied by an increased UCP1 expression, was explained as adaptive response of enzymatic activities on decreased superoxide $\left(\mathrm{O}_{2}{ }^{-}\right)$production by uncoupling [9]. However, with the exception of the data on acute cold-exposure [12], the results on molecular mechanisms involving this SODs adaptation are still lacking. Precisely, it is unknown how SODs expression, in terms of protein and mRNA level, changes during various periods of acclimation to cold.

On the other hand, it has been shown that reactive species first of all nitric oxide (NO) and $\mathrm{O}_{2}{ }^{--}$also participate in numerous redox-sensitive pathways that regulate different IBAT functions [9, 11, 13-15]. NO has been reported to regulate tissue blood flow [16], proliferation and differentiation of brown adipocytes, apoptosis [9], capillary remodeling [11] and mitochondriogenesis [13, 15]. It regulates some of these pathways directly, but the targeting of some NO effects in IBAT has been found to be mediated by $\mathrm{O}_{2}{ }^{-}$and glutathione $[10,13,14]$. Thus, the enzymes involved in reactive species metabolism became an essential component of redox signaling, tightly regulating and targeting ROS and RNS production, which is crucial for their effects.

Nevertheless, despite the vast knowledge on the role NO plays in IBAT thermogenesis, there is still no data on possible effects of NO on both Mn- and CuZn-SOD mRNA and protein expression, especially during transition to the new tissue homeostatic state, i.e. in multiple stages of acclimation to cold.

Because of all aforementioned facts, we performed this time-course study to gain a better insight into the regulatory molecular mechanisms underlying SODs activity adaptation during cold-exposure by examining $\mathrm{Mn}$ - and CuZn-SOD mRNA and protein content in IBAT of rats kept at cold for different time periods. A special attention has been paid to a possible influence of NO on coldinduced expressional profiles of IBAT SOD isoforms. For this purpose, adult male rats kept at room temperature, or exposed to cold for 1, 3, 7, 12, 21 and 45 days and receiving NO-manipulating agents L-arginine or $N^{\omega}$-nitroL-arginine methyl ester (L-NAME) as drinking liquids were used. Changes in $\mathrm{Mn}-$ and $\mathrm{CuZn}$-SOD mRNA and protein level, total SOD (tSOD) activity, UCP1 and nitrotyrosine immunopositivity and activation of nuclear factor- $\kappa \mathrm{B}(\mathrm{NF}-\kappa \mathrm{B})$, a potential mediator of $\mathrm{NO}$ effects, were assessed.

\section{Materials and Methods}

Animals

The experimental protocol was approved by the Ethical Committee for the Treatment of Experimental Animals of the Institute for Biological Research, Belgrade. Mill Hill hybrid hooded, 4-month-old rat (Rattus norvegicus Berkenhout 1769) males were divided into two main groups: a control group, kept at room temperature $\left(22 \pm 1^{\circ} \mathrm{C}\right)$ for the duration of the experiment, and the second group, maintained at cold $\left(4 \pm 1^{\circ} \mathrm{C}\right)$. Cold-acclimated group was divided into three subgroups: (1) untreated; (2) L-argininetreated and (3) L-NAME-treated. Drugs were administered as drinking liquids, containing $2.25 \%$ solution of L-arginine $\cdot \mathrm{HCl}$, i.e. $0.01 \%$ L-NAME $\cdot \mathrm{HCl}$ in tap water, as described earlier $[9,11]$. The rats were housed in individual plastic cages with drinking liquids and food ad libitum. The duration of cold-exposure ranged from 1 to 45 days $(1,3,7$, 12,21 and 45 days), with six animals per experimental group.

The animals were killed at each experimental point by decapitation, and the IBAT was harvested and quickly cut into halves on an ice bath. Approximately one half of the tissue was snap-frozen in liquid nitrogen and stored at $-80^{\circ} \mathrm{C}$ until subsequent RNA extraction and western blotting. The remaining IBAT part was used for immunohistochemistry and total SOD activity determination. For immunohistochemical examination, fresh tissue was immediately fixed in neutral buffered formalin and subjected to light microscopy. For SOD activity determination, tissue samples were homogenized (a Janke and Kunkel $\mathrm{Ka} /$ Werke Ultra/Turrax homogenizer) at $0-4{ }^{\circ} \mathrm{C}$ in $0.25 \mathrm{M}$ sucrose, $0.1 \mathrm{mM}$ EDTA and $50 \mathrm{mM}$ Tris buffer, $\mathrm{pH} 7.4$ and sonicated.

\section{RNA extraction and semi-quantitative RT-PCR}

Total RNA was prepared from $100 \mathrm{mg}$ of isolated IBAT using TRIzol (Invitrogen, Life Technologies, CA, USA) and one microgram of total RNA was reverse transcribed to cDNA using an iScript $^{\mathrm{TM}}$ cDNA synthesis kit (Bio Rad Laboratories, USA) according to manufacturer's instructions.

PCR reaction was performed on a thermal cycler (Perkin Elmer Gene Amp PCR System 2004) as done previously [17]. The sequences and cycle protocols for used primers are listed in Table 1. Band intensities were quantified by Gel Doc XM System (Bio Rad Laboratories, USA) equipped with Quantity One ${ }^{\circledR}$ software (Software for Bio Rad's Image Analysis system, Version 4.6.0). Expression of transcripts was calculated as the ratio of intensities of genes and 18S rRNA house-keeping gene, used as an 
Table 1 Primers sequences and cycling conditions

\begin{tabular}{|c|c|c|c|}
\hline Gene & Sequence & Product size (bp) & Cycle number \\
\hline \multicolumn{4}{|l|}{$M n S O D$} \\
\hline Forward & $5^{\prime}$-CGCAGCTAGGAATAATGGAA-3' & 649 & 33 \\
\hline Reverse & 5'-TTATGACCCGCACTTACTGG-3' & & \\
\hline Cycle protocol & $60^{\prime \prime}$ at $95^{\circ} \mathrm{C}, 60^{\prime \prime}$ at $57^{\circ} \mathrm{C}, 90^{\prime \prime}$ at $72^{\circ} \mathrm{C}$ & & \\
\hline \multicolumn{4}{|l|}{ CuZnSOD } \\
\hline Forward & 5'-TGGGGACAATACACAAGG-3' & 359 & 33 \\
\hline Reverse & 5'-TAGCAGGACAGCAGATGA-3' & & \\
\hline Cycle protocol & $60^{\prime \prime}$ at $95^{\circ} \mathrm{C}, 60^{\prime \prime}$ at $53^{\circ} \mathrm{C}, 90^{\prime \prime}$ at $72^{\circ} \mathrm{C}$ & & \\
\hline \multicolumn{4}{|l|}{$18 s$ rRNA } \\
\hline Forward & 5'-CGCAGCTAGGAATAATGGAA-3' & 860 & 33 \\
\hline Reverse & 5'-TTATGACCCGCACTTACTGG-3' & & \\
\hline Cycle protocol & $30^{\prime \prime}$ at $95^{\circ} \mathrm{C}, 30^{\prime \prime}$ at $56^{\circ} \mathrm{C}, 30^{\prime \prime}$ at $72^{\circ} \mathrm{C}$ & & \\
\hline
\end{tabular}

internal control. The results were expressed in percentages in relation to control values taken as $100 \%$.

\section{SDS-PAGE and western blotting}

Western blot was done as described previously [9, 11] using mouse monoclonal antibody against Mn-SOD (1:1000, Chemicon International Inc., Temecula, CA, USA) and rabbit polyclonal antibody against $\mathrm{CuZn-SOD}$ (1:200, Santa Cruz Biotechnology, Santa Cruz, CA, USA). Protein concentrations are expressed relative to the control acclimated to room temperature taken as $100 \%$. Quantitative analysis of immunoreactive bands was done by ImageQuant software. Volume is the sum of all the pixel intensities within a band; 1 pixel $=0.007744 \mathrm{~mm}^{2}$.

Immunohistochemistry

Five- $\mu$ m-thick sections were immunostained with the avidin-biotin-peroxidase method, as described previously [9]. Primary antibodies were anti-nitrotyrosine, anti-UCP1 (1:200 and 1:300 Abcam, Cambridge, UK, respectively) and anti-NF- $\kappa \mathrm{B}(1: 200, \mathrm{v} / \mathrm{v}$ Upstate, USA). The specificity of the immune reaction was tested by replacing primary antibody with a non-immune rabbit serum or by incubating the sections with the secondary antibody alone.

\section{Activity of superoxide dismutase}

Total SOD activity was examined [18] and enzymatic activity expressed in $\mathrm{U} \mathrm{mg}^{-1}$ protein. SOD units were defined as the amount of the enzyme inhibiting epinephrine oxidation by $50 \%$ under the appropriate reaction conditions.
Other assays and statistics

Protein content was estimated using bovine serum albumin as a reference [19]. Analysis of variance (ANOVA) was used for within-group comparison of the data. If the $\mathrm{F}$ test showed an overall difference, Tukey's test was applied to evaluate significance of the differences. Statistical significance was accepted at $P<0.05$.

\section{Results}

Changes in Mn-SOD and CuZn-SOD mRNA content in rats kept at low temperature and treated with L-arginine or L-NAME are depicted in Fig. 1. As seen from Fig. 1a, Mn-SOD mRNA level in untreated rats was decreased on day 1 , increased on day $3(P<0.001)$, while on day 7 was at control level to decline from day 12 to 45 below control $(P<0.001)$. In L-arginine-treated group, Mn-SOD transcript amount was higher than that of the control on days 3 and 7 of cold-acclimation $(P<0.001)$, but below the control in all remaining experimental time points (Fig. 1b). Concomitantly, Mn-SOD mRNA level was higher on days $1,3,7$ and 45 in relation to untreated group. In L-NAMEtreated group (Fig. 1c) abundance of Mn-SOD transcript was higher than in the control only on day $3(P<0.01)$ to be decreased below control in all remaining time points $(P<0.001)$. Compared to untreated group, Mn-SOD mRNA level in L-NAME-treated group was lower from day 3 to day 21 of cold-acclimation. Similarly, CuZn-SOD mRNA amount in untreated rats was below control $(P<0.05)$ on day one of cold-acclimation (Fig. 1d), while on day 3 it was higher than the control $(P<0.001)$. Further, on day 7, CuZn-SOD mRNA amount was at the 
A
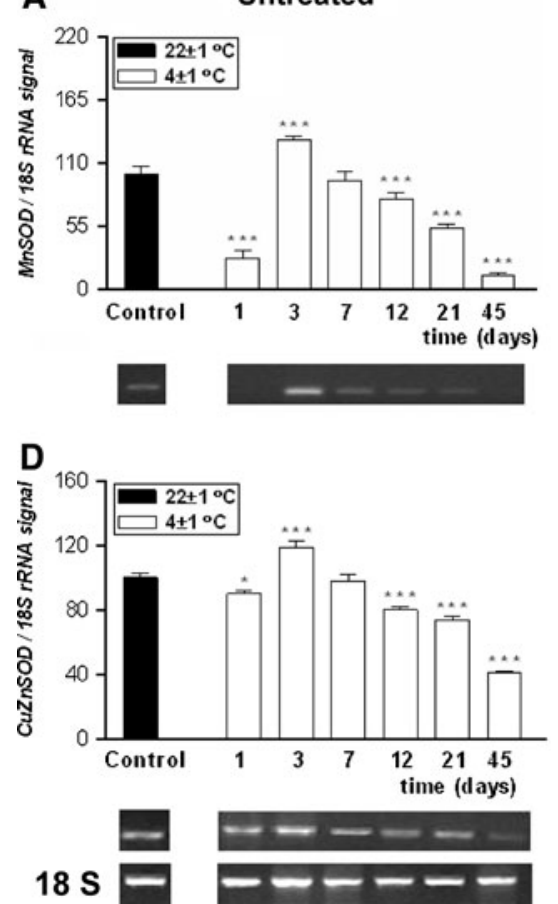

B

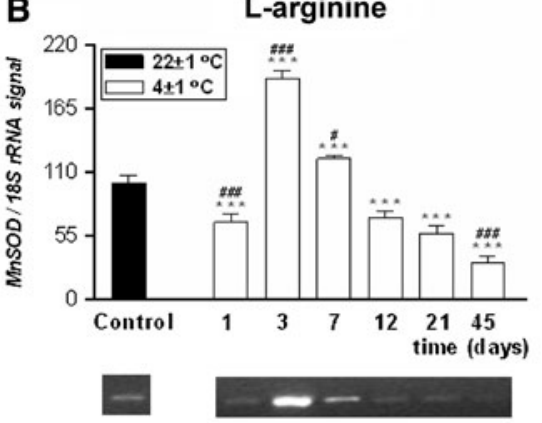

E

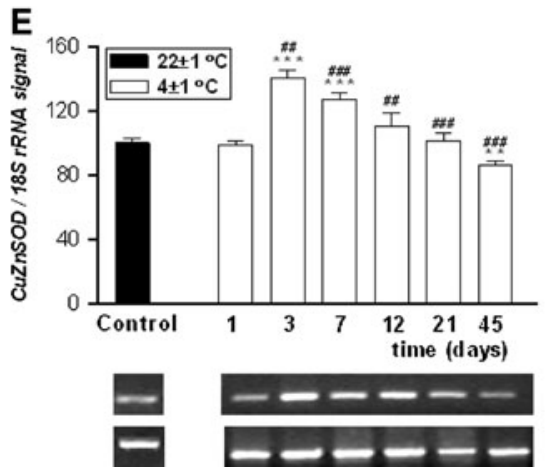

C

L-NAME
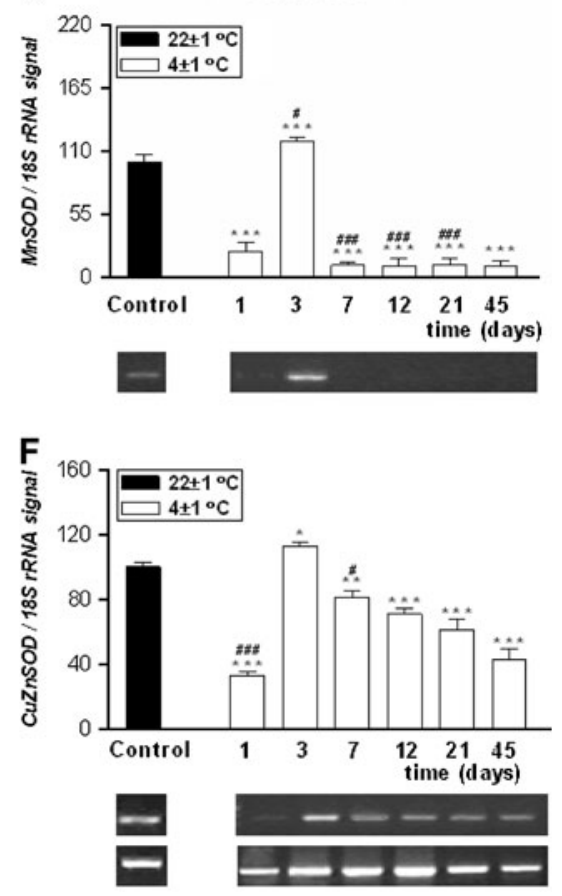

Fig. 1 Time-dependent changes in Mn-SOD and CuZn-SOD mRNA amount in IBAT of untreated (Fig. 1a, d, respectively), L-arginine(Fig. 1b, e, respectively) and L-NAME-treated (Fig. 1c, f, respectively) rats exposed to cold for different time-periods. Data obtained after quantification of Mn-SOD and CuZn-SOD mRNA bands by Quantity One ${ }^{\circledR}$ software (Software for Bio Rad's Image Analysis system, Version 4.6.0). Expressions of transcripts were calculated as the ratio of intensities of Mn-SOD and CuZn-SOD genes and 18S

control level and from day 12 to day 45 was below control value $(P<0.001)$. In $\mathrm{L}$-arginine-treated group, $\mathrm{CuZn}$-SOD mRNA level (Fig. 1e) was higher compared with the control from day 3 to day 7 of cold-acclimation, while lower mRNA amount in relation to the control was detected no sooner than on day $45(P<0.01)$. Also, comparing with the value found in untreated group, the amount of CuZn-SOD transcript in L-arginine-treated group was higher from day 3 to day 45. In L-NAME-treated group, CuZn-SOD mRNA amount was higher than the control on day $3(P<0.05)$ of cold-acclimation, while being below control in all remaining experimental time points (Fig. 1f). Also, CuZn-SOD mRNA level in L-NAME-treated rats was lower on days 1 and 7 when compared with untreated group.

Time-dependent changes in Mn-SOD and CuZn-SOD protein content are depicted in Fig. 2. In all groups kept at cold, Mn-SOD protein level was lower in comparison with the control during the entire acclimation period, except on day 3 when its increased expression was observed in untreated group (Fig. 2a) and on day one in L-NAMEtreated group (Fig. 2c) when its expression was at the control level. Compared with untreated group, L-arginine
rRNA house-keeping gene. Relative mRNA levels are presented as percentages of control acclimated to room temperature taken as $100 \%$. The quantification data represents the mean \pm S.E.M. of three independent experiments. *Comparison with the control, $* P<0.05$; ** $P<0.01 ; \quad * * * P<0.001$; \#comparison of L-arginine- or L-NAME-treated group with untreated group in the same time point, ${ }^{\#} P<0.05 ;{ }^{\# \#} P<0.01 ;{ }^{\# \# \#} P<0.001$

decreased (Fig. 2b), while L-NAME increased Mn-SOD protein content in all experimental time points, except on day 3 (Fig. 2c). It can be seen also, that neither cold nor L-arginine and L-NAME treatments affected CuZn-SOD protein expression (Figs. 2d, e, f, respectively).

Alterations in tSOD activity in IBAT showed that during the whole period of acclimation to cold, tSOD activity was decreased in both untreated and L-arginine-treated animals, compared with the control (Fig. 3). However, tSOD activity in L-NAME-treated rats was decreased from day 1 to day 12 of acclimation, it was at the control level on day 21 , to become significantly increased on day 45 in relation to the control $(P<0.001)$. Besides, tSOD activity in L-NAME-treated group was higher on days 21 and 45 than those detected in untreated group in the same time points.

Immunohistochemical detection of UCP1 is presented in Fig. 4. In control group, a weak cytoplasmic immunoreaction of UCP1 was detected. In untreated groups, already after one day of exposure to cold, markedly increased UCP1 immunopositivity was observed and the immunoreaction reached the maximum on day 3 of cold-acclimation. Later on, during the acclimation to cold, UCP1 immunopositivity was continuously weakening to become equal to the control 

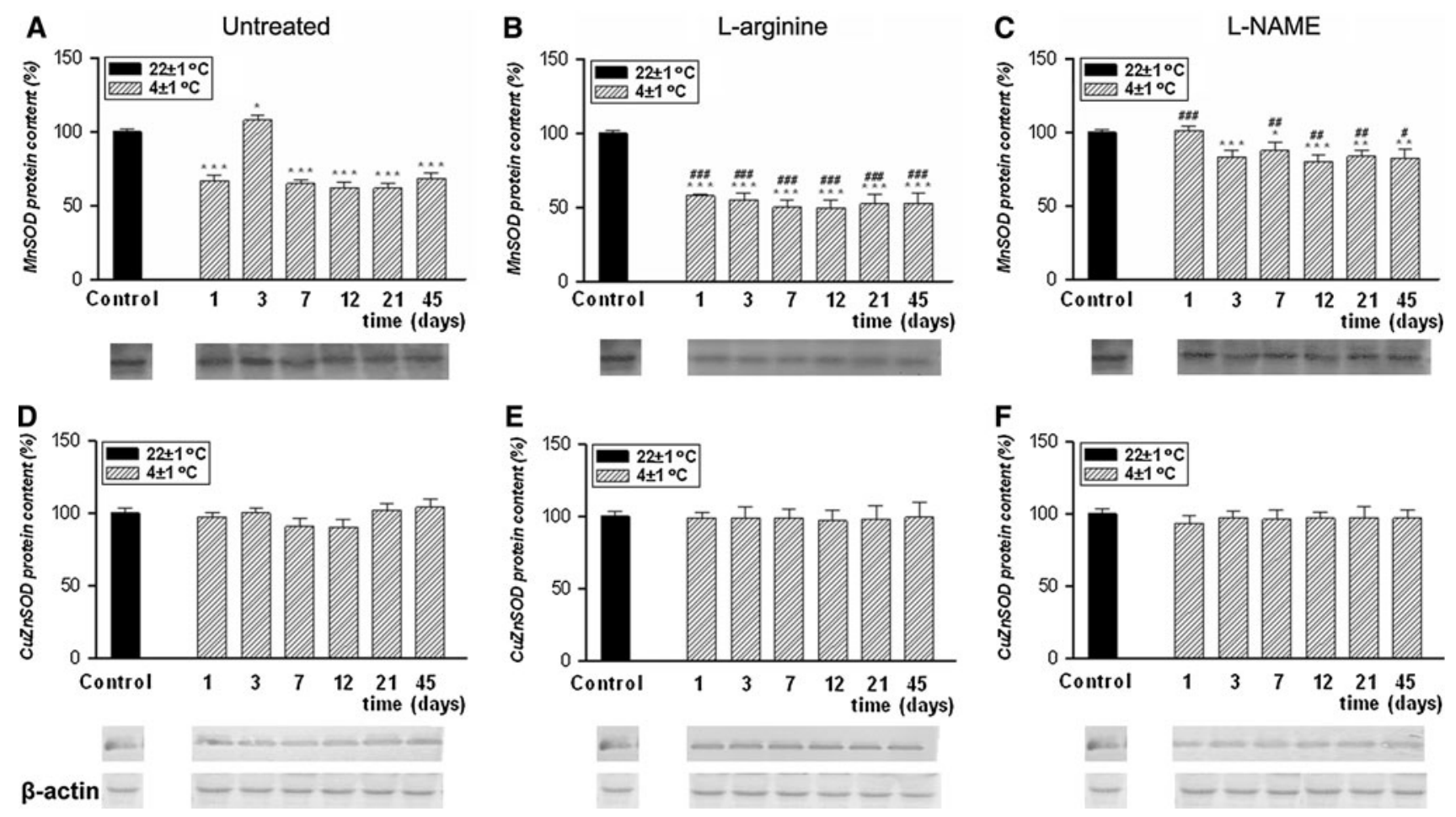

Fig. 2 Time course of changes in Mn-SOD and CuZn-SOD protein content in IBAT of untreated (Fig. 3a, d, respectively), L-arginine(Fig. 3b, e, respectively) and L-NAME-treated (Fig. 3c, f, respectively) rats acclimated to low temperature. Western blotting was performed using specific antibody against Mn-SOD and CuZn-SOD. The results of a representative experiment from three observations are shown. Data obtained after quantification of Mn-SOD and CuZn-SOD protein bands by ImageQuant software. Relative protein concentrations are expressed

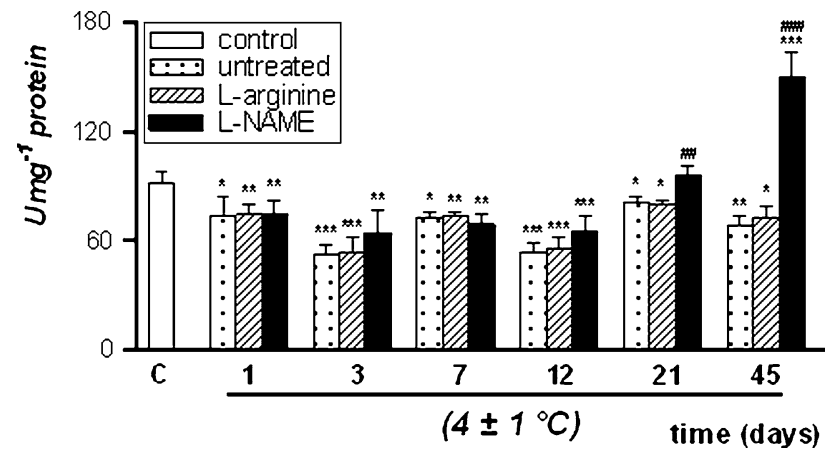

Fig. 3 Time course of tSOD activity changes in IBAT of untreated, L-arginine- and L-NAME-treated rats kept at low temperature. *Comparison with the control, $* P<0.05 ; * * P<0.01 ; * * * P<0.001$. ${ }^{\#}$ Comparison of L-arginine- or L-NAME-treated group with untreated group in the same time point, ${ }^{\# \#} P<0.01 ;{ }^{\# \# \#} P<0.001$

no sooner than on day 45 . In addition to cold, L-arginine acted increasingly on UCP1 immunopositivity. Namely, a stronger UCP1 immunoreaction in relation to the control was recorded throughout the entire 45-day-period of coldacclimation, and these immunopositivities were stronger than those of untreated group. In L-NAME treated rats stronger than control, UCP1 immunopositivity was detected in relation to the control acclimated to room temperature taken as $100 \%$. Values represent the means \pm S.E.M. from three independent experiments. *Comparison with the control, $* P<0.05 ; * * P<0.01$; $* * * P<0.001$; ${ }^{*}$ comparison of L-arginine- or L-NAME-treated group with untreated group in the same time point, ${ }^{\#} P<0.05$; ${ }^{\# \#} P<0.01$; ${ }^{\# \# \#} P<0.001$. Volume is the sum of all the pixel intensities within a band; 1.0 pixel $=0.007744 \mathrm{~mm}^{2}$

from day 1 to day 12 . However, these immunoreactions were weaker in relation to those observed in untreated group in the same experimental time points of cold-acclimation.

$\mathrm{NF}-\kappa \mathrm{B}$ immunolabeling in IBAT is shown in Fig. 5. $\mathrm{NF}-\kappa \mathrm{B}$ nuclear translocation, which represents its activation, was detected on day 3 of cold-acclimation in untreated group and on days 3 and 7 in L-arginine-treated animals. However, no NF- $\kappa \mathrm{B}$ immunolabeling in brown adipocyte nuclei of L-NAME treated rats was recorded.

Immunohistochemical detection of nitrotyrosine in IBAT is presented in Fig. 6. In control rats, a weak cytoplasmic immunoreaction of nitrotyrosine, also present in a few nuclei, was detected. In untreated rats, nitrotyrosine was labeled only on day 3 of acclimation to cold. In L-argininetreated animals, nitrotyrosine immunopositivity was observed on days 3 and 7, while in L-NAME-treated group it was not detected during the entire cold-acclimation period.

\section{Discussion}

The data obtained throughout the present work showed that cold, as an indispensable part of IBAT thermogenic 
Fig. 4 Immunohistochemical UCP1 detection in IBAT of untreated, L-arginine- and L-NAME-treated rats acclimated to cold. Immunohistochemical detection of UCP1 was performed using specific antibody against UCP1. Magnification: $\times 40$, orig. Scale bars-20 $\mu \mathrm{m}$

\section{Control}

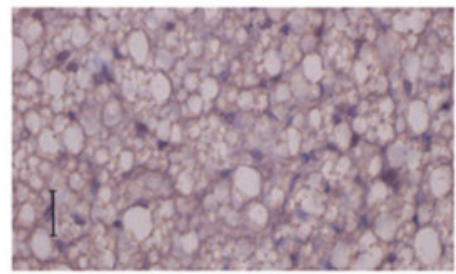

Untreated
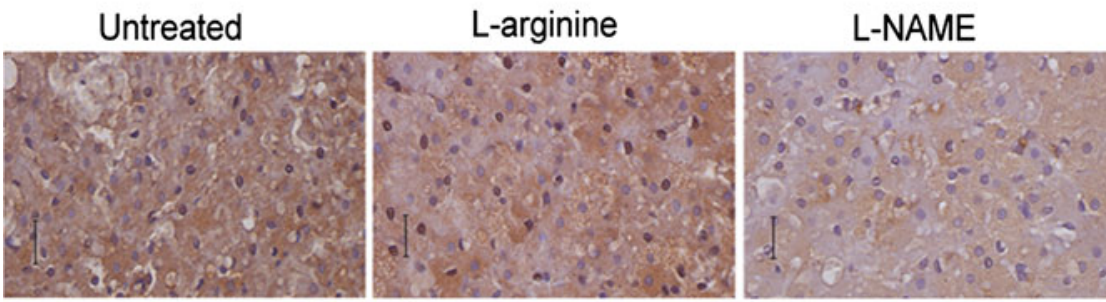

Day 1
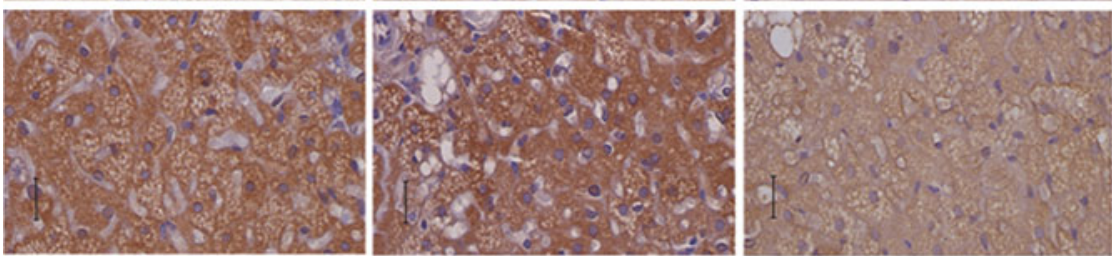

Day 3
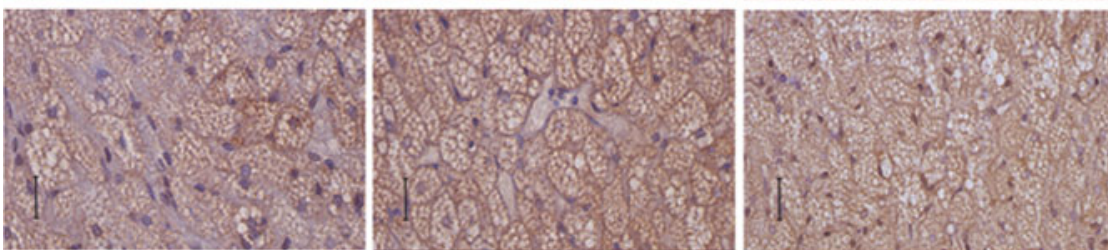

Day 7
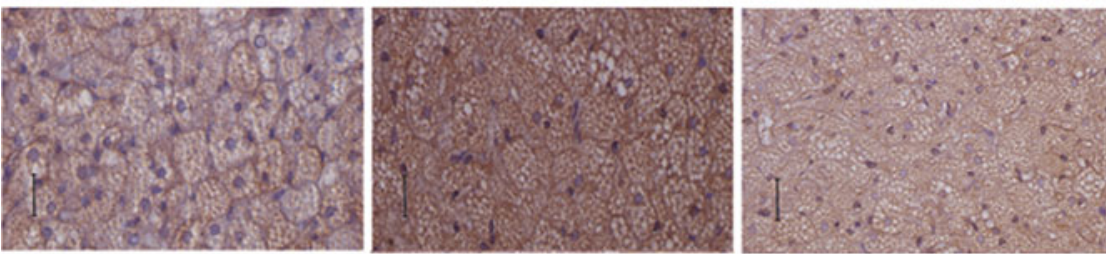

Day 12
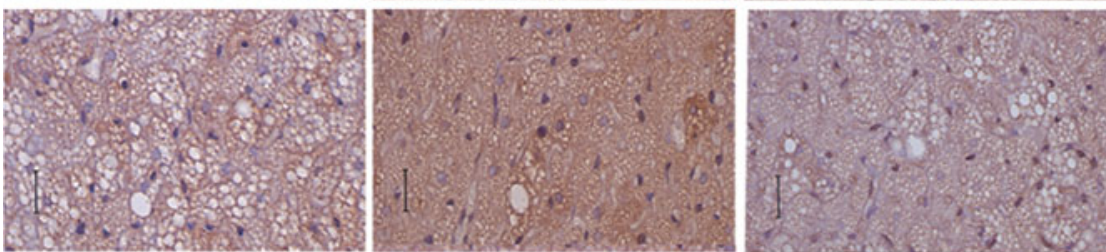

Day 21
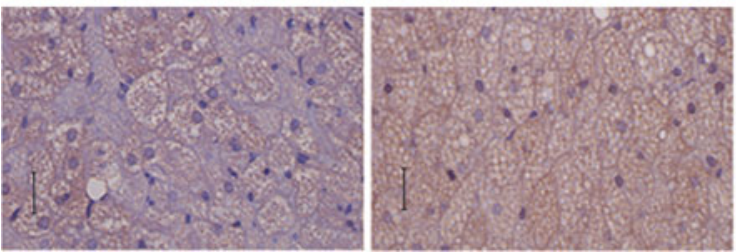

program, increased UCP1 immunopositivity in untreated rats during the entire 45-day-acclimation period. In line with this and the fact that uncoupling acts decreasing production of $\mathrm{O}_{2}{ }^{-}$in IBAT mitochondria [20, 21], decreased tSOD activity during the entire examined acclimation period was observed. Similarly, one-day-cold- exposure decreased both Mn- and CuZn-SOD mRNA expression. This is in line with
Niakao et al. [12] who have shown that acute cold exposure rapidly decreased mRNA level of all SOD isoforms. However, on day 3 of cold-acclimation, both $\mathrm{Mn}$ - and CuZn-SOD transcripts were higher than the control and this was followed by restitution of their expression at control level on day 7 and a decrease below control until the end of experimental period. This SODs transcriptional activation is in 
Fig. 5 Immunohistochemical detection of NF- $\kappa$ B in IBAT sections of untreated, L-arginine- and L-NAMEtreated rats acclimated to cold for different time periods. Immunohistochemical detection of NF- $\kappa$ B was performed using specific antibody against NF- $\kappa$ B. Magnification: $\times 40$, orig. Scale bars $-20 \mu \mathrm{m}$
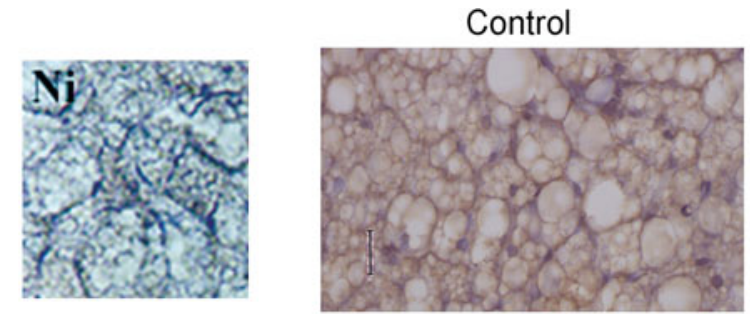

Untreated

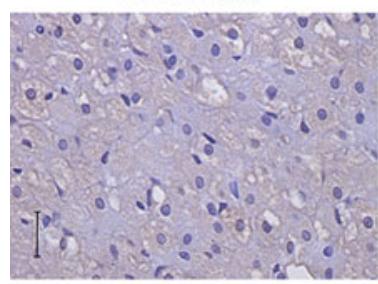

L-arginine
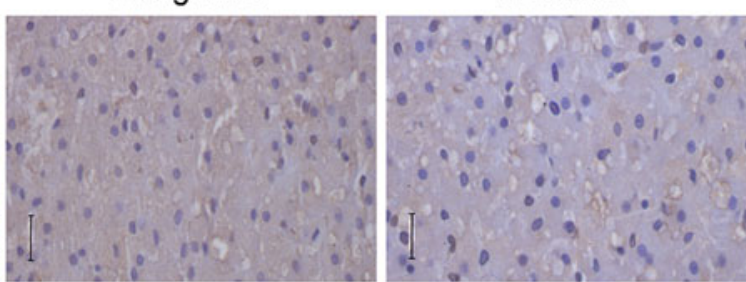

Day 1
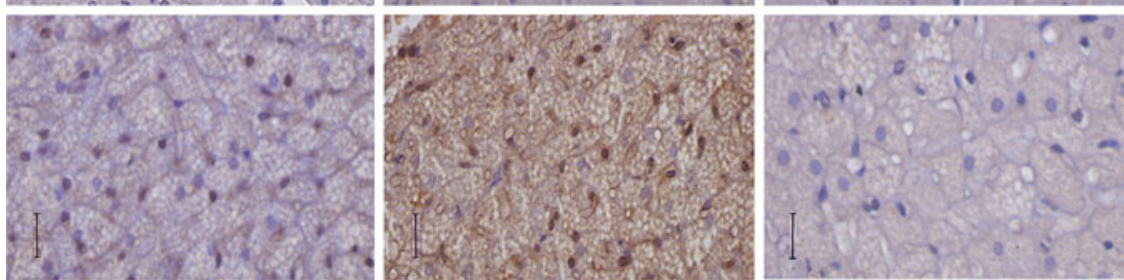

Day 3
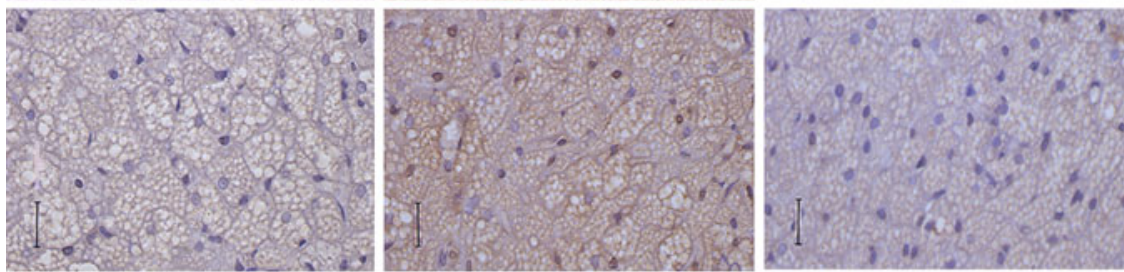

Day 7
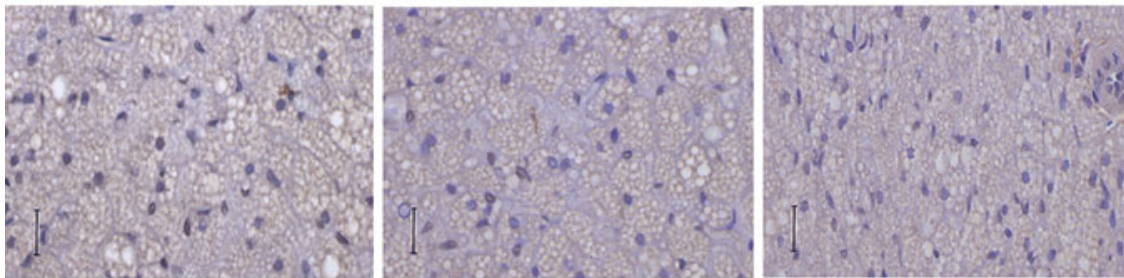

Day 12
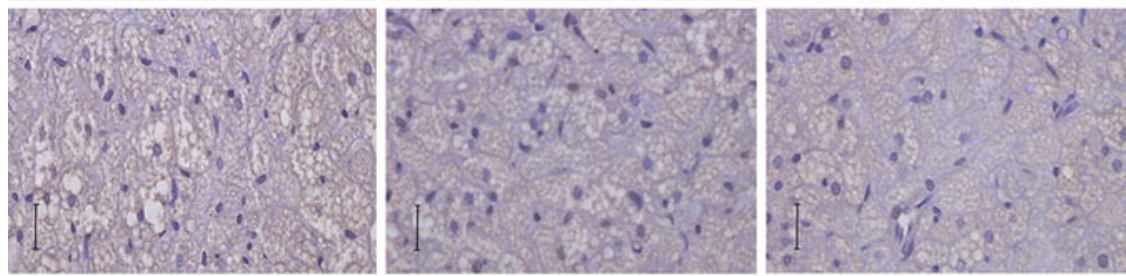

Day 21
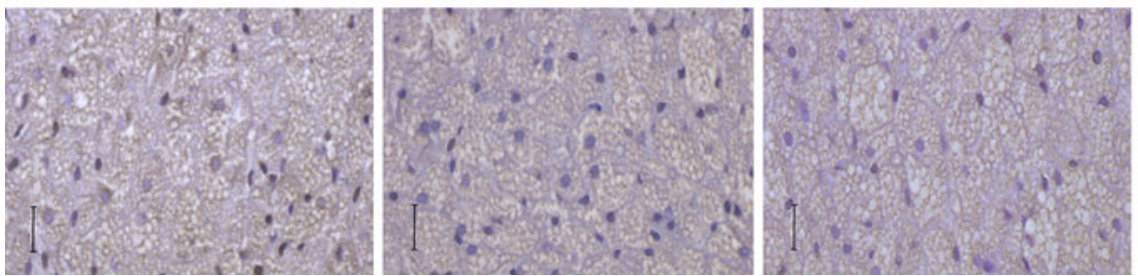

Day 45 accordance with our recent data demonstrating maximal transcriptional activation of IBAT thermogenic genes, leading to tissue metabolic adaptation on day 3 of coldacclimation [22]. These results clearly reflect intensification of IBAT synthetic processes and metabolic rate oriented to preserve thermal homeostasis. During that time, IBAT $\mathrm{O}_{2}$ consumption can increase tremendously, which could transiently increase ROS production and activate AD. 

detection of nitrotyrosine in IBAT of untreated, L-arginineand L-NAME-treated rats exposed to different time periods of cold.

Immunohistochemical detection of nitrotyrosine was performed using specific antibody against nitrotyrosine. Magnification: $\times 40$, orig. Scale bars $-20 \mu \mathrm{m}$
Fig. 6 Immunohistochemical
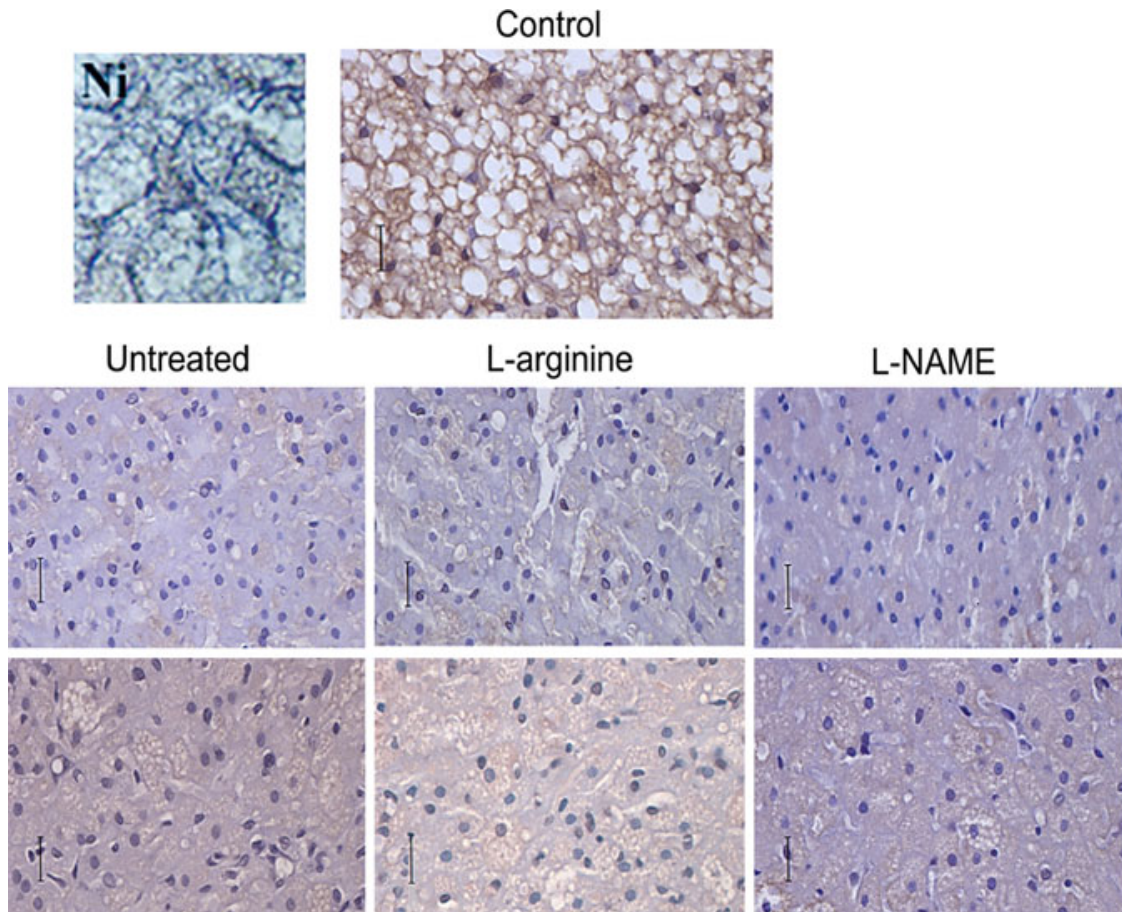

Day 1
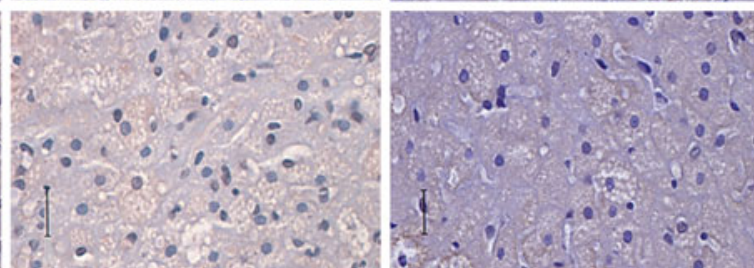

Day 3
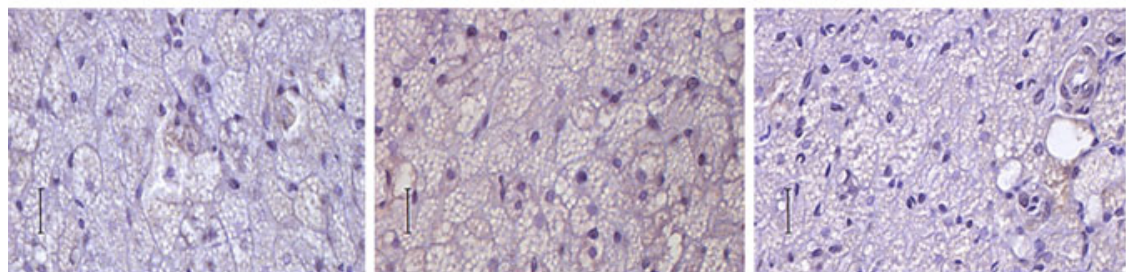

Day 7
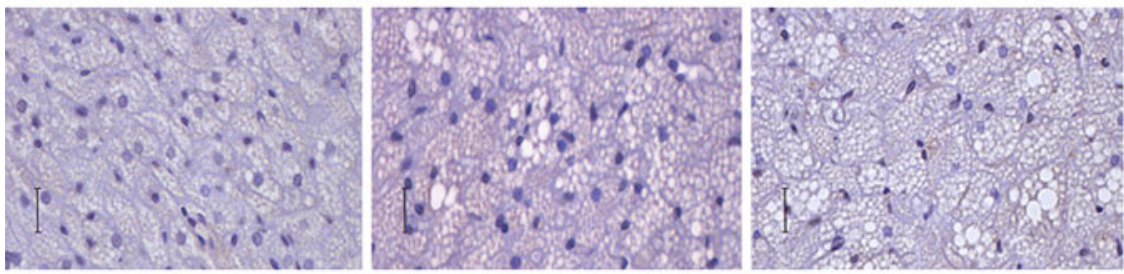

Day 12
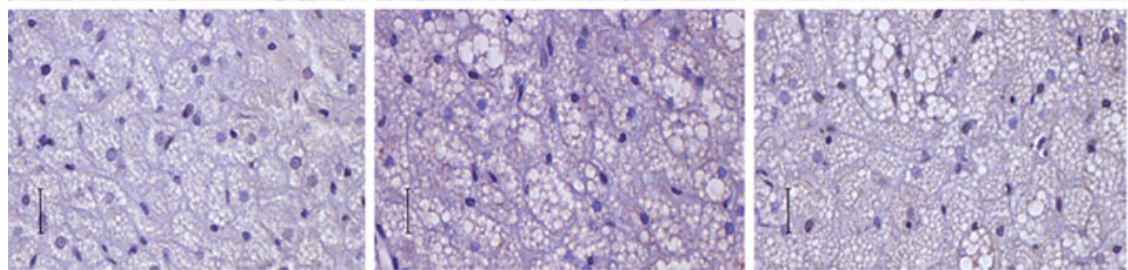

Day 21
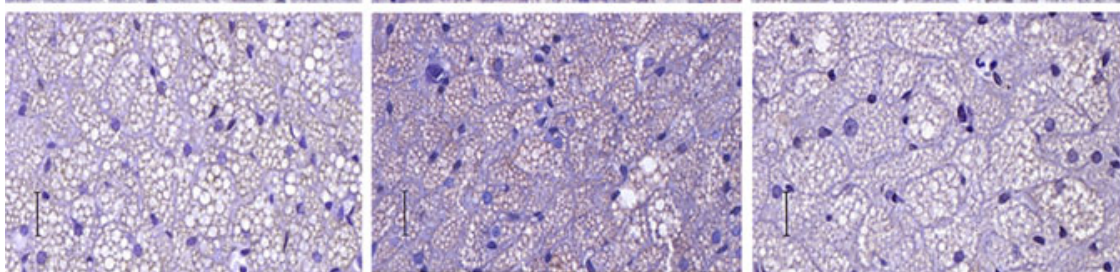

Day 45

Accordingly, activation of NF- $\kappa \mathrm{B}$ was recorded here on day 3 of cold-acclimation, clearly confirming above hypothesized tissue redox perturbations. Namely, NF- $\kappa \mathrm{B}$ is the major redox sensitive factor shown to activate gene expression of a number of antioxidative enzymes [23].

Therefore, it could be involved in the activation of SODs transcription observed in the present study.

Besides, we have shown recently that NO participates in the activation of IBAT thermogenic gene expression during cold-acclimation [24]. Thus, we have examined here IBAT 
appearance of nitrotyrosine, a redox signaling component that mediates a variety of NO actions $[25,26]$. The data showed that time-course of SODs transcriptional activation correlates well with nitrotyrosine immunopositivity increase, suggesting NO involvement in this signaling. However, it has been shown that during the time of exposure to cold, the rate of uncoupling increases and consequently, mitochondrial production of $\mathrm{O}_{2}{ }^{-}-$decreases $[21,27]$. Accordingly, after transient activation of SODs transcription on day 3 , their mRNA expression was decreased and remained below control value until the end of cold-acclimation. Thus, a prolonged decrease in the abundance of $\mathrm{Mn}$ - and CuZn-SOD transcripts observed here strongly indicates that previously shown adaptive decrease in SODs activities on uncoupling-decreased $\mathrm{O}_{2}{ }^{-}$ production $[10,11]$ is achieved already at the level of their transcription.

On the other hand, in most tissues examined, coldinduced changes in the SOD isoenzyme mRNA levels appeared not to be concomitant with those in the protein levels as reported by Niakao et al. [12]. These authors emphasized that this is particularly accurate in IBAT in which acute cold-exposure rapidly decreased expression of all SOD isoforms without any alteration in the amount of the enzymatic proteins. This is in accordance with our results on the changes of $\mathrm{CuZn-SOD}$ expression demonstrating that neither low temperature nor either of the applied treatments affected protein expression of this enzyme. However, changes in Mn-SOD protein expression were in line with the changes in mRNA expression of untreated rats during acclimation to cold. These data support the fact that $\mathrm{CuZn-SOD}$ is a highly stable protein [25] and the data revealing Mn-SOD more inducible than CuZnSOD in conditions of metabolic turnover [28, 29].

The observed different response of $\mathrm{Mn}$ - and $\mathrm{CuZn-SOD}$ mRNA and protein levels during cold-acclimation appears to depend on their different subcellular localization. Namely, Mn-SOD is compartmentalized in the mitochondria, whereas CuZn-SOD mainly occurs in the cytosol [15]. Thus, the changes in Mn-SOD protein expression reflect the state in these compartments and the observed decrease could be explained by adaptive response of the enzyme on decreased production of $\mathrm{O}_{2}{ }^{-}$by an intense uncoupling.

Compared with cold, treatment with L-arginine, a substrate for NO synthesis, augmented and prolonged period of increased Mn- and CuZn-SOD mRNA expression, as well as UCP1 immunolabeling, while L-NAME markedly attenuated mRNA expression of both SOD isoforms and decreased UCP1 immunopositivity. Such opposite effects of L-arginine and L-NAME strongly indicate that stimulatory effects of L-arginine, could be, at least in part, mediated by NO. Further support of this hypothesis is provided by the results on immunohistochemical staining of nitrotyrosine that was higher than the control on day 3 and day 7 of cold-acclimation. Stimulatory effect of NO on UCP1 appearance in IBAT is in line with our previous data showing induction of UCP1 protein expression by NO [10]. On the other hand, induction of $\mathrm{Mn}$ - and $\mathrm{CuZn-SOD}$ transcription by L-arginine strongly suggests that $\mathrm{NO}$ activates IBAT SODs transcription and agrees well with the results of other authors obtained both in vitro [30] and in vivo [31, 32] and showing that both SOD isoforms contain NO-binding sites and that their transcription could be up-regulated by NO. In addition, Mn-SOD gene promoter contains $\mathrm{NF}-\kappa \mathrm{B}$ binding site and represents one of key targets for NF- $\kappa \mathrm{B}$ signaling [33]. Accordingly, nuclear localization of P65 NF- $\kappa \mathrm{B}$ subunit, which signals its activation, was detected in the present study from day 3 to day 7 of L-arginine treatment. Considering that $\mathrm{NO}$ can up-regulate NF- $\kappa \mathrm{B}[34,35]$, it could be supposed that the observed stimulatory effect of NO on Mn-SOD expression might also be mediated by $\mathrm{NF}-\kappa \mathrm{B}$ activation. However, precise mechanisms involved in the regulation of IBAT SODs mRNA expression by NO remain to be elucidated.

As already stated, in accordance with tissue active-, i.e. thermogenic-state characterized by an intensive uncoupling, Mn-SOD protein expression was generally decreased in all groups during the acclimation to cold, except on day 3 in untreated and day one in L-NAME-treated animals. The same holds true for tSOD activity decrease and UCP1 labeling increase observed throughout this work during the entire period of acclimation to cold. However, the values of Mn-SOD protein expression were lower in L-argininetreated group in each time-point of cold-acclimation, in relation to those detected in untreated rats. This result is in line with our previous data showing stimulatory effect of NO on cold-induced increase of UCP1 protein expression [10] and mitochondriogenesis [13]. Thus, this might reflect enzymatic response at protein level on NO-induced increase of uncoupling and thermogenic capacity. In addition, an assumed decrease in $\mathrm{O}_{2}{ }^{-}$availability could be the consequence of its interaction with NO. These molecules are rapidly reacting with the threefold higher rate constant than that of dismutation reaction catalyzed by SOD [36]. In this context, $\mathrm{NO}$ may act as $\mathrm{O}_{2}{ }^{--}$scavenger, thus decreasing its concentration. Interaction of these redox molecules leads to the formation of peroxynitrite [37], RNS that takes part in NO cGMP-independent signaling and mediates variety of NO actions, such as induction of Mn-SOD gene expression without concomitant response in the protein level $[22,38]$. Precisely, alongside with stimulatory effect of peroxynitrite on Mn-SOD transcription, it inactivates Mn-SOD via nitration causing either a decrease of its activity or its protein level [38]. In vivo effects of peroxynitrite are possible to observe by nitrotyrosine formation [39-41]. So, nitrotyrosine appearance detected here 
in L-arginine-treated group on day 3 and 7 of cold-acclimation, accompanied by Mn-SOD mRNA expression increase and its protein expression decrease, indicate that peroxynitrite could play a role in the regulation of IBAT Mn-SOD mRNA and protein expression.

In general, the results of the present study corroborate and extend our earlier findings demonstrating that adaptive decrease in SODs activity on uncoupling-decreased $\mathrm{O}_{2}{ }^{-}$ production is achieved already at the level of gene transcription. Our data also clearly demonstrated that besides regulating various IBAT functions, $\mathrm{NO}$ is implicated in the regulation of IBAT SOD isoforms, while differentially affecting mRNA, protein content and SODs activities. Furthermore, NO increases tissue thermogenic capacity in thermogenically active IBAT, through increased UCP1 expression and uncoupling. Thus, it seems likely that primary effect of NO on IBAT during cold-acclimation is to reinforce tissue thermogenic capacity and that during this acting NO indirectly modulates the response of IBAT SOD isoforms.

Acknowledgments This work was supported by the Ministry of Science and Technological Development of the Republic of Serbia, Grant No 143050 and by the COST FA0602 Action.

Conflict of interest statement The authors declare that there are no conflicts of interest.

\section{References}

1. Himms-Hagen J (1990) Brown adipose tissue thermogenesis: interdisciplinary studies. FASEB J 4:2890-2898

2. Nicholls DG, Locke RM (1984) Thermogenic mechanisms in brown fat. Physiol Rev 64:1-64

3. Cannon B, Nedergaard J (1986) Brown adipose tissue thermogenesis in neonatal and cold-adapted animals. Biochem Soc Trans 14:233-236

4. Suter ER (1969) The fine structure of brown adipose tissue. II. Perinatal development in the rat. Lab Invest 21:246-258

5. Halliwell B, Gutteridge JM (1990) The antioxidants of human extracellular fluids. Arch Biochem Biophys 280:1-8

6. Buzadžić B, Blagojević D, Korać B, Saičić ZS, Spasić MB, Petrović VM (1997) Seasonal variation in the antioxidant defense system of the brain of the ground squirrel (Citellus citellus) and response to low temperature compared with rat. Comp Biochem Physiol C 117:141-149

7. Buzadžić B, Korać B, Petrović VM (1999) The effect of adaptation to cold and re-adaptation to room temperature on the level of glutathione in rat tissues. J Therm Biol 24:373-377

8. Korać B, Buzadžić B (2001) Doxorubicin toxicity to the skin: possibility of protection with antioxidants enriched yeast. J Dermatol Sci 25:45-52

9. Petrović V, Korać A, Buzadžić B, Korać B (2005) The effects of L-arginine and L-NAME supplementation on redox-regulation and thermogenesis in interscapular brown adipose tissue. J Exp Biol 208:4263-4271

10. Petrović V, Buzadžić B, Korać A, Vasilijević A, Janković A, Korać B (2006) Free radical equilibrium in interscapular brown adipose tissue: relationship between metabolic profile and antioxidative defense. Comp Biochem Physiol C 142:60-65

11. Korać A, Buzadžić B, Petrović V, Vasilijević A, Janković A, Mićunović K, Korać B (2008) The role of nitric oxide in remodeling of capillary network in rat interscapular brown adipose tissue after long-term cold-acclimation. Histol Histopathol 23:441-450

12. Niakao C, Ookawara T, Kizaki T, Suzuki K, Haga S, Sato Y, Ohno H (1999) Effects of acute cold stress on mRNA expression and immunoreactivity of three superoxide dismutase isoenzymes in genetically obese mice. Res Commun Mol Pathol Pharmacol 106:47-61

13. Petrović V, Korać A, Buzadžić B, Vasilijević A, Janković A, Mićunović K, Korać B (2008) Nitric oxide regulates mitochondrial re-modelling in interscapular brown adipose tissue: ultrastructural and morphometric-stereologic studies. J Microsc 232:542-548

14. Nisoli E, Clementi E, Tonello C, Sciorati C, Briscini L, Carruba MO (1998) Effects of nitric oxide on proliferation and differentiation of rat brown adipocytes in primary cultures. Br J Pharmacol 125:888-894

15. Nisoli E, Clementi E, Paolucci C, Cozzi V, Tonello C, Sciorati C, Bracale R, Valerio A, Francolini M, Moncada S, Carruba MO (2003) Mitochondrial biogenesis in mammals: the role of endogenous nitric oxide. Science 299:896-899

16. Kikuchi-Utsumi K, Gao B, Ohinata H, Hashimoto M, Yamamoto N, Kuroshima A (2002) Enhanced gene expression of endothelial nitric oxide synthase in brown adipose tissue during cold-exposure. Am J Physiol Regul Integr Comp Physiol 282:623-626

17. Petrović V, Buzadžić B, Korać A, Vasilijević A, Janković A, Korać B (2009) L-Arginine supplementation induces glutathione synthesis in interscapular brown adipose tissue through activation of glutamate-cysteine ligase expression: the role of nitric oxide. Chem Biol Interact 182:204-212

18. Misra HP, Fridovich I (1972) The role of superoxide anion in the autooxidation of epinephrine and a simple assay for superoxide dismutase. J Biol Chem 247:3170-3175

19. Lowry OH, Rosenbrough NJ, Farr AL, Randall RJ (1951) Protein measurement with the Folin phenol reagent. J Biol Chem 193:265-275

20. Cino M, Del Maestro RF (1989) Generation of hydrogen peroxide by brain mitochondria: the effect of reoxygenation following postdecapitative ischemia. Arch Biochem Biophys 269:623-638

21. Skulachev VP (1994) Decrease in the intracellular concentration of $\mathrm{O}_{2}$ as a special function of cellular respiratory system. Biokhimiia 59:1910-1912

22. Jackson RM, Parish G, Helton ES (1998) Peroxynitrite modulates Mn-SOD gene expression in lung epithelial cells. Free Radic Biol Med 25:463-472

23. Ji LL (2007) Modulation of skeletal muscle antioxidative defense by exercise: role of redox signaling. Free Radic Biol Med 44:142-152

24. Petrović V (2008) Influence of L-arginine and L-NAME on enzymes involved in metabolism of nitric oxide, carbon monoxide and superoxide anion radical, during cold-induced IBAT hyperplasia. Dissertation, University of Belgrade

25. Foster MW, McMahon TJ, Stamler JS (2003) S-nitrosylation in health and disease. Trends in Mol Med 9:160-168

26. Stamler JS, Lamas S, Fang FC (2001) Nitrosylation: the prototypic redox-based signaling mechanism. Cell 106:675-683

27. Boveris A, Oshino N, Chance B (1972) The cellular production of hydrogen peroxide. Biochem J 128:617-630

28. Petrović VM, Saičić ZS, Radojičić R, Buzadžić B, Spasić BM (1989) Difference in the inducibility between copper zinc containing superoxide dismutase and manganese containing superoxide dismutase activity in the brown adipose tissue of the rat 
exposed or adapted to cold; correlation with tissue hyperplasia. Iugosl Physiol Pharmacol Acta 25:33-38

29. Perera CS, St Clair DK, McClain CJ (1995) Differential regulation of manganese superoxide dismutase activity by alcohol and TNF in human hepatoma cells. Arch Biochem Biophys 323:471-476

30. Sano H, Hirai M, Saito H, Nakashima I, Isobe KI (1997) A nitric oxide-releasing reagent, S-nitroso-N-acetylpenicillamine, enhances the expression of superoxide dismutases mRNA in the murine macrophage cell line RAW264-7. Immunology 92:118-122

31. Frank S, Zacharowski K, Wray GM, Thiemermann C, Pfeilschifter J (1999) Identification of copper/zinc superoxide dismutase as a novel nitric oxide-regulated gene in rat glomerular mesangial cells and kidneys of endotoxemic rats. FASEB J 13:869-882

32. Keller T, Plesková M, McDonald MC, Thiemermann C, Pfeilschifter J, Beck KF (2003) Identification of manganese superoxide dismutase as a NO-regulated gene in rat glomerular mesangial cells by 2D gel electrophoresis. Nitric Oxide 9:183-193

33. Guo G, Yan-Sanders Y, Lyn-Cook BD, Wang T, Tamae D, Ogi J, Khaletskiy A, Li Z, Weydert C, Longmate JA, Huang TT, Spitz DR, Oberley LW, Li JJ (2003) Manganese superoxide dismutasemediated gene expression in radiation-induced adaptive responses. Mol Cell Biol 23:2362-2378

34. Connelly L, Palacios-Callender M, Ameixa C, Moncada S, Hobbs AJ (2001) Biphasic regulation of NF- $\kappa$ B activity underlies the pro- and anti-inflammatory actions of nitric oxide. $\mathrm{J}$ Immunol $166: 3873-3881$
35. Connelly L, Jacobs AT, Palacios-Callender M, Moncada S, Hobbs AJ (2003) Macrophage endothelial nitric-oxide synthase autoregulates cellular activation and pro-inflammatory protein expression. J Biol Chem 278:26480-26487

36. Huie RE, Padmaja S (1993) The reaction of NO with superoxide. Free Radic Res Commun 18:195-199

37. Patel RP, Darley-Usmar VM (1996) Using peroxynitrite as oxidant with low-density lipoprotein. Methods Enzymol 269:375384

38. Nilakantan V, Halligan NL, Nguyen TK, Hilton G, Khanna AK, Roza AM, Johnson CP, Adams MB, Griffith OW, Pieper GM (2005) Post-translational modification of manganese superoxide dismutase in acutely rejecting cardiac transplants: role of inducible nitric oxide synthase. J Heart Lung Transplant 24:1591-1599

39. Govindaraju K, Shan J, Levesque K, Hussain SN, Powell WS, Eidelman DH (2008) Nitration of respiratory epithelial cells by myeloperoxidase depends on extracellular nitrite. Nitric Oxide 18:184-194

40. Lavi S, Yang EH, Prasad A, Mathew V, Barsness GW, Rihal CS, Lerman LO, Lerman A (2008) The interaction between coronary endothelial dysfunction, local oxidative stress, and endogenous nitric oxide in humans. Hypertension 51:127-133

41. Hu J, Ng YK, Chin CM, Ling EA (2007) Effects of L-arginine and $\mathrm{N}(\mathrm{G})$-nitro-L-arginine methyl ester treatments on expression of neuronal nitric oxide synthase in the guinea-pig bladder after partial bladder outlet obstruction. Neuroscience 151:680-691 